\title{
ИСПОЛЬЗОВАНИЕ ОСАДКОГЕЛЕОБРАЗУЮЩЕЙ КОМПОЗИЦИИ ДЛЯ СНИЖЕНИЯ ОБВОДНЕННОСТИ СКВАЖИН НА НЕФТЯНОЙ ЗАЛЕЖИ С ВЫСОКОВЯЗКОЙ НЕФТЬЮ
}

Поплыгина Ирина Сергеевна', davydova_irina@bk.ru

\author{
Мордвинов Виктор Антонович', \\ mva44@bk.ru \\ Пермский национальный исследовательский политехнический университет, \\ Россия, 616990, г. Пермь, Комсомольский пр., 29.
}

Актуальность. Обводнение добывающих скважин - естественный процесс при разработке нефтяных месторождений. На процесс обводнения скважин в первую очередь влияет неоднородность коллектора по фильтрационным свойствам - послойная (по разрезу) и зональная (по простиранию), наличие подошвенной воды, водонефтяных зон, повышенная вязкость пластовой нефти. Скорость перемещения фронта вытеснения увеличивается в высокопроницаемых слоях, что ускоряет процесс преждевременного обводнения скважин.

Цель: выделить наиболее эффективные технологии водоизоляции в Пермском крае и исследовать возможность их использования на конкретном месторождении.

Объект: карбонатные залежи с высоковязкой нефтью Ножовской группы месторождений в Пермском крае. Средняя вязкость пластовой нефти для 8 объектов разработки в отложениях турнейского яруса (Т) составляет 72,1 мПа*с при высоком значении коэффициента расчлененности $(6,23)$. Средние значения соотношения обводненности и выработки запасов нефти доходят до 1,8. В таких условиях необходимо проведение работ по ограничению притока воды в добывающие скважины.

Методы: анализ результатов выполненных работ по снижению обводненности скважин, гидродинамическое моделирование водоизоляционных и потоковыравнивающих работ в скважинах на нефтяном месторождении.

Результаты. В Пермском крае более высокая эффективность при ограничении притока воды в добывающие скважины по промытым слоям для пластов с карбонатным коллектором отмечена для геле- и осадкообразующих технологий. В нагнетательных скважинах работы по выравниванию профилей приемистости осуществлялись в основном с применением цементов, смол и полиакриламида. Высокую эффективность показала технология с использованием осадко- и гелеобразующих компонентов на основе лигносульфонатов. Выполнено моделирование работы элемента залежи с использованием осадко- и гелеобразующих веществ для участка Березовского нефтяного месторождения. Приемистость верхнего интервала снизится на 82 \% при проведении водоизоляционных работ. По добывающим скважинам в течение года обводненность снижается на $3 . .15$ \%, а суммарный дебит по нефти увеличивается на 0,9 т/сут.

Ключевые слова:

Обводненность, водоизоляция, осадкогелеобразующие технологии, лигносульфонаты.

\section{Введение}

Обводнение добывающих скважин при разработке нефтяных месторождений - естественный процесс, связанный с заполнением водой освобождающегося от нефти порового пространства продуктивных пластов. При равномерном продвижении фронта вытеснения вода достигает интервала перфорации добывающей скважины по всей вскрытой (перфорированной) толще пласта и скважина практически полностью обводняется за короткий промежуток времени. В реальных условиях продолжительность безводного периода работы скважин может изменяться от нулевых значений до многих месяцев, что связано с влиянием на процесс обводнения геолого-физических особенностей нефтяной залежи, в первую очередь неоднородности коллектора по фильтрационным свойствам - послойной (по разрезу) и зональной (по простиранию), наличием подошвенной воды, водонефтяных зон, повышенной вязкости пластовой нефти [1-4]. Скорость перемещения фронта в таких слоях увеличивается, что ускоряет процесс преждевременного обводнения скважин [5, 6]. Влияние неоднородности коллектора усиливается при повышенной и высокой вязкости пластовой нефти. По мере заполнения нефтенасыщенного пласта вытесняющей водой и перемещения фронта вытеснения в направлении добывающей скважины гидравлические сопротивления в высокопроницаемых слоях постоянно снижаются. Наличие слоев горных пород с системами раскрытых сообщающихся трещин, что особенно характерно для карбонатных коллекторов, ускоряет процесс обводнения добывающих скважин.

Промытые и изолированные перемычками от нефтенасыщенных пропластков водонасыщенные слои в интервалах между нагнетательными и добывающими скважинами характеризуются, как правило, повышенными давлениями, под действием которых при достаточно длительных остановках скважин вода оттесняет нефть от забоев добывающих скважин и снижает фазовую проницаемость горных пород для нефти в призабойных зонах.

\section{Объект исследования}

В Пермском крае один из блоков залежей с высоковязкой нефтью приурочен к Ножовской группе месторождений [7]. Средняя вязкость пластовой нефти для 8 объектов разработки в отложениях 
турнейского яруса (Т) составляет 72,1 мПа*с при высоком значении коэффициента расчлененности $(6,23)$. Повышенной вязкостью нефти характеризуются объекты в тульских (Тл), тульско-бобриковских (Тл-Бб) и башкирских (Бш) отложениях. В табл. 1 приведены средние по объектам разработки данные о выработке запасов нефти и обводненности продукции скважин в условиях поддержания пластового давления путем закачки воды в пласт. При наиболее неблагоприятных в отношении обводненности добывающих скважин условиях отношение «обводненность -выработка запасов» по турнейским объектам в 1,4 раза выше, чем для других объектов. На рис. 1 в качестве примера приведена динамика соотношения «обводненность-отбор» для турнейских объектов Березовского (1) и Западного (2) месторождений. Отклонение от «нормального» тренда таково, что без проведения работ по ограничению обводненности скважин выработка извлекаемых запасов при граничных условиях (обводненность $98 \%$ и выше) может быть не обеспечена.

Таблииа 1. Выработка извлекаемых запасов и обводненность продукции скважин (осредненные данные)

Table 1. Issued investments and water production of wells (averaged data)

\begin{tabular}{|c|c|c|c|c|c|c|c|}
\hline 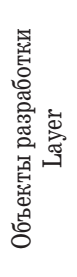 & 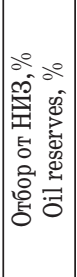 & 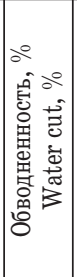 & 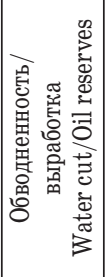 & 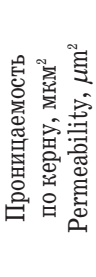 & 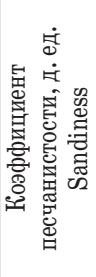 & 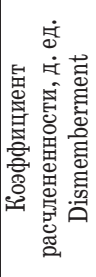 & 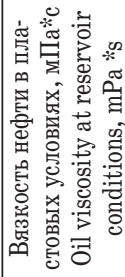 \\
\hline $\begin{array}{l}\mathrm{T} \\
\mathrm{T}\end{array}$ & 39,79 & 56,46 & 1,42 & 0,17 & 0,42 & 6,23 & 72,1 \\
\hline $\begin{array}{l}\text { Тл, Бб } \\
\text { Tl, Bb }\end{array}$ & 65,81 & 66,89 & 1,02 & 0,71 & 0,57 & 2,50 & 23,5 \\
\hline $\begin{array}{l}\text { Бш } \\
\text { Bhs }\end{array}$ & 38,33 & 41,93 & 1,09 & 0,15 & 0,37 & 5,18 & 11,1 \\
\hline
\end{tabular}

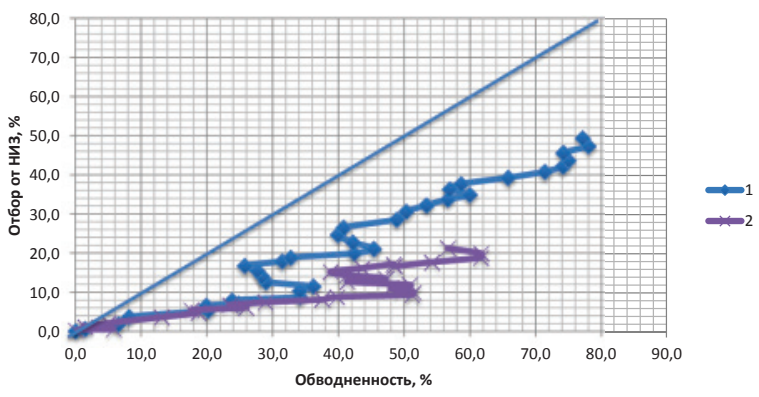

Pис. 1. Обводненность и выработка запасов нефти

Fig. 1. Watercut and development of oil reserves

\section{Анализ технологической эффективности работ по ограничению водопритока в скважины}

Известно, что для замедления процесса обводнения добывающих скважин целесообразно проведение работ в нагнетательных скважинах по вы- равниванию профилей приемистости [8-12], включая закачку растворов полимеров [13-16], использование других технологий [17]. При этом более эффективны мероприятия по так называемому системному воздействию, когда работы по выравниванию профилей приемистости в нагнетательной и водоизоляционные работы в добывающей скважинах скоординированы во времени.

На рис. 2 и в табл. $2[18,19]$ представлены результаты более 300 ВИР (водоизоляционных работ) на нефтяных месторождениях Пермского края за 15 лет (до 2015 г. включительно). Более высокая эффективность при ограничении притока воды по промытым слоям для пластов с карбонатным коллектором отмечена для геле- и осадкообразующих технологий.

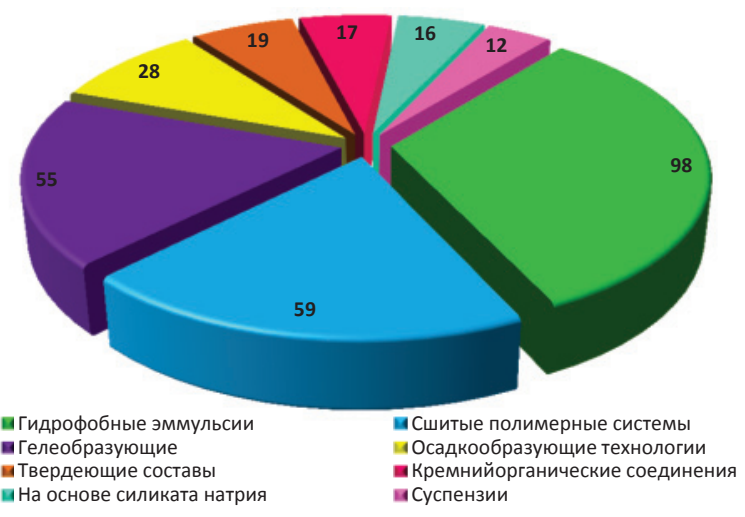

Pис. 2. Распределение технологий водоизоляционных работ в скважинах

Fig. 2. Distribution of waterproofing technology works in wells

таблица 2. Результаты водоизоляиионных работ на добывающих скважинах

Table 2. Results of work to limit the water content of production wells

\begin{tabular}{|c|c|c|}
\hline $\begin{array}{c}\text { Вид состава } \\
\text { Type of composition }\end{array}$ & $\begin{array}{c}\text { Продолжительность } \\
\text { эффекта (снижение } \\
\text { обводненности), сут } \\
\text { Duration of effect } \\
\text { (reduction of water- } \\
\text { cut), days }\end{array}$ & $\begin{array}{c}\text { Снижение } \\
\text { обводнен- } \\
\text { ности \% } \\
\text { Reduction } \\
\text { of water- } \\
\text { cut, \% }\end{array}$ \\
\hline \begin{tabular}{|l|} 
Гелеобразующие \\
Gel-forming compounds
\end{tabular} & 971 & 16,6 \\
\hline $\begin{array}{l}\text { Гидрофобные эммульсии } \\
\text { Hydrophobic emulsion }\end{array}$ & 667 & 16,6 \\
\hline $\begin{array}{l}\text { Кремнийорганические соединения } \\
\text { Organosilicon compounds }\end{array}$ & 650 & 18,0 \\
\hline $\begin{array}{l}\text { Суспензии } \\
\text { Suspensions }\end{array}$ & 591 & 3,3 \\
\hline $\begin{array}{l}\text { Твердеющие составы } \\
\text { Cements }\end{array}$ & 514 & 31,5 \\
\hline $\begin{array}{l}\text { Сшитые полимерные системы } \\
\text { Crosslinked Polymer Systems }\end{array}$ & 253 & 9,3 \\
\hline $\begin{array}{l}\text { На основе силиката натрия } \\
\text { Based on sodium silicate }\end{array}$ & 163 & 38,0 \\
\hline $\begin{array}{l}\text { Осадкообразующие технологии } \\
\text { Sediment Formation Technologies }\end{array}$ & 142 & 13,0 \\
\hline $\begin{array}{l}\text { Средние значения } \\
\text { Average values }\end{array}$ & 494 & 18,3 \\
\hline
\end{tabular}


В нагнетательных скважинах работы по выравниванию профилей приемистости (ВПП) осуществлялись в основном с применением цементов, смол и полиакриламида.

На месторождениях Ножовской группы за последние годы в добывающих скважинах турнейских объектов водоизоляционные работы проводились с применением водного раствора гидролизованного полиакриламида ОВП-2 (6 скважин) и кремнийорганического вещества (1 скважина). На башкирских объектах в 7 скважинах для ВИР использовали ОВП-2, на одной скважине - цементный раствор. Для скважин с ОВП-2 снижение обводненности составило, в среднем, 7 \% при продолжительности эффекта около 3 месяцев. При обработке скважин АКОР-БН обводненность снизилась с 97,2 до 96 \% при кратковременном әффекте.

На нагнетательном фонде работы по ВВП осуществлялись с применением составов на основе полиакриламида. По 10 скважинам средний прирост добычи нефти по реагирующим добывающим скважинам составил 1,2 т/сут, средняя дополнительная добыча в расчете на одно мероприятие - 160 т.

Регулирование профилей приемистости нагнетательных скважин за счет ограничения проницаемости продуктивных пород может быть достигнуто применением различных методов и способов, основанных на формировании в высокопроницаемых пластах зон с повышенными гидравлическими сопротивлениями за счет высокой вязкости закачиваемой жидкости или изменения структуры пустотного пространства в процессе пластового осадкообразования. Вязкостное ограничение приемистости высокопроницаемых интервалов недостаточно эффективно из-за непродолжительного времени действия эффекта. Известные технологии регулирования профилей приемистости, основанные на внутрипластовом осадко- и гелеобразовании, характеризуются различной степенью воздействия (селективности) по отношению к пластам, отличающимся проницаемостью, насыщаю- щими флюидами и вещественным составом горных пород.

На одной нагнетательной скважине (№ 351) выравнивание профиля приемистости проведено с применением разработанного в ПНИПУ осадкогелеобразующего лигносульфонатно-нефтяного состава [20]. Средний дебит по нефти для реагирующих добывающих скважин увеличился на 1,9 т/сут, дополнительная добыча нефти составила около 980 т при продолжительности эффекта более полугода. Состав включал сернокислый алюминий, технический лигносульфонат марки $\mathrm{A}$, безводную нефть и соляную кислоту (менее $1 \%$ ).

По данным термометрии до проведения мероприятия закачиваемая в скважину вода (приемистость $150 \mathrm{~m}^{3} /$ сут) поступала в основном в промытую верхнюю часть интервала перфорации. Сразу после обработки приемистость верхних интервалов снизилась до 18 \% от общей приемистости (рис. 3).

С данным составом выполнены опытно-промышленные работы на трех элементах пласта БС-10 Усть-Балыкского нефтяного месторождения [21]. Каждый элемент включал одну нагнетательную и реагирующие добывающие скважины. По элементу с нагнетательной скважиной № 1624 работа добывающих скважин с повышенным дебитом продолжалась в течение трех месяцев, по элементам с нагнетательными скважинами № 1627 и 1646 продолжительность эффекта (по дополнительной добыче нефти) составила более одного года. В целом дополнительная добыча нефти по трем элементам превысила 11,5 тыс. т при работе добывающих скважин с обводненностью, сниженной, в среднем, в 1,25 раза (до мероприятия 44,2\%, после ГТМ - 35,4%). Исследования по определению профиля приемистости после ВПП проведены на скв. 1627. Коэффициент работающей толщины увеличился с 0,4 до 0,68. Приемистость верхних пропластков уменьшилась с 250 до $173 \mathrm{~m}^{3}$ /сут, доля не принимавших воду до ГТМ нижних пропластков в общей приемистости составила $52 \%$.
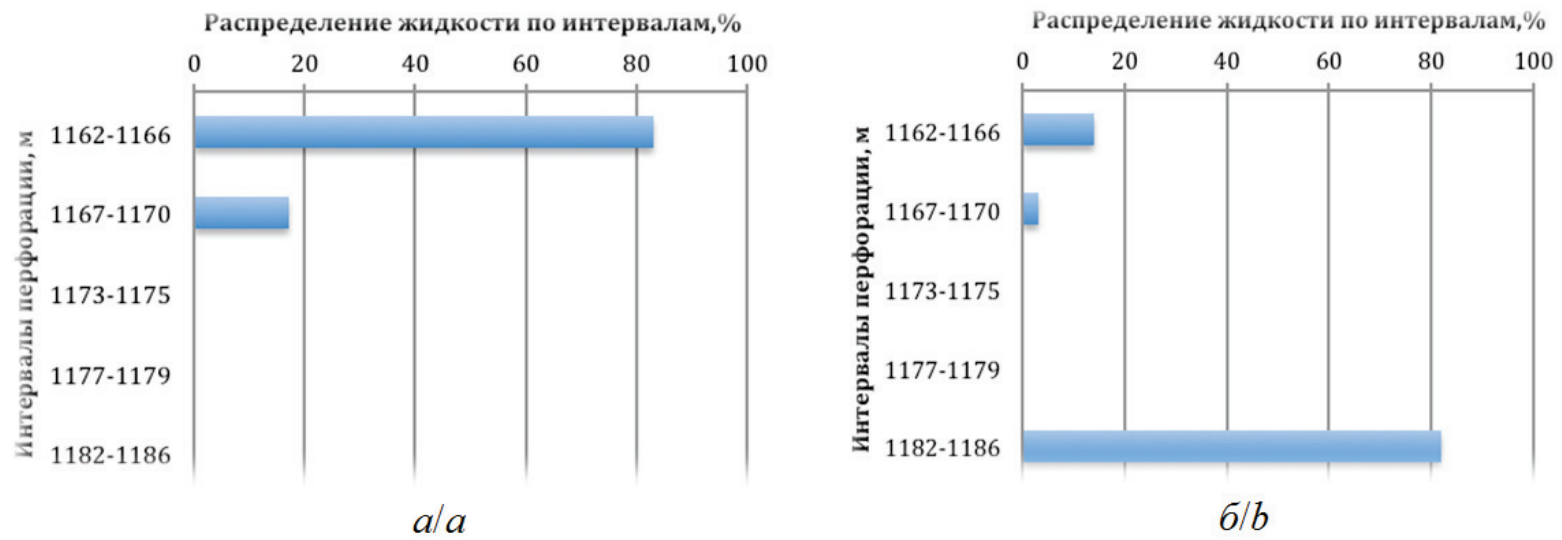

Рис. 3. Профиль приемистости скважины до (а) и после (б) использования состава ОЛИНС

Fig. 3. Profile injectivity of the well before (a) and after (b) use of the composition OLINS 
Гидродинамическое моделирование водоизоляционных и потоковыравнивающих работ в скважинах на нефтяном месторождении

При анализе состояния разработки турнейских объектов Ножовской группы месторождений выделена залежь южного купола Березовского месторождения (рис. 4), включающая нагнетательную скв. 779 и действующие добывающие скважины № 727,780 и 933 .

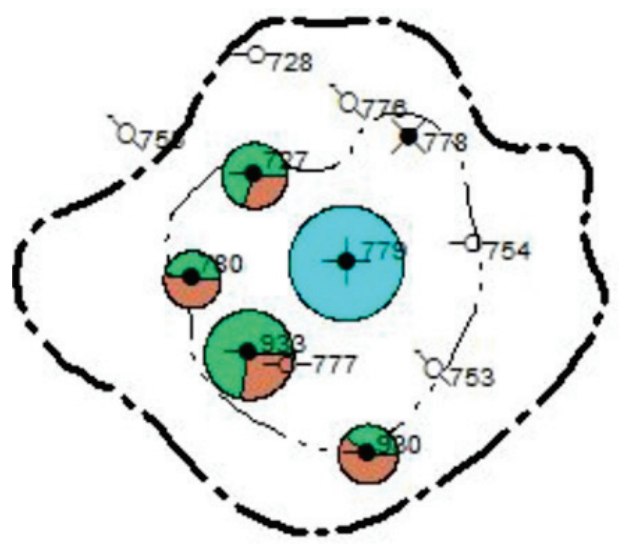

Pис. 4. Участок турнейской залежи Березовского месторождения

Fig. 4. Plot of the Tournaisian reservoir of the Berezovsky field

Средний дебит по нефти скважин составляет 3,27 т/сут, средняя обводненность $67,4 \%$. Обводненность превышает выработку запасов в целом по турнейской залежи месторождения в 1,57 раза. В нагнетательной скв. 779 с приемистостью $30 \mathrm{~m}^{3} /$ сут около $80 \%$ закачиваемой воды уходит в верхний интервал перфорации. В программном

\section{СПИСОК ЛИТЕРАТУРЫ}

1. Study on the influence of injection/production type and well pattern and spacing on producing degree of thin and poor layers / S. Liang, Y. Liu, N. Zhang, B. Zeng // Journal of Petroleum Exploration and Production Technology. - 1 September 2018. V. 8. - Iss. 3. - P. 861-870.

2. Кудряшова Д.А Использование вероятностно-статистических методов для определения источников обводнения скважинкандидатов для водоизоляционных работ (на примере визейского объекта месторождения Пермского края) // Вестник Пермского национального исследовательского политехнического университета. Геология. Нефтегазовое и горное дело. 2018. - T. 17. - № 1. - C. $26-36$.

3. Кочнева 0.Е., Лимонова К.Н. Оценка обводненности скважин и продукции яснополянской залежи Москудьинского месторождения // Вестник Пермского национального исследовательского политехнического университета. Геология. Нефтегазовое и горное дело. - 2014. - Т. 13. - № 10. - С. 66-72.

4. Experimental studies on production performance of oil reservoirs with bottom water / C. Liu, K. Li, X. Tian, G. Zhao, Y. Chen, B.M. Mahlalela // Journal of Petroleum Science and Engineering.- January 2019. - V. 172. - P. 527-537.

5. Characteristics and mechanism of water production for fractured vuggy carbonate reservoirs, Halahatang Oilfield / H. Min, L. Chen, L. Wang, L. Zhang, J. Chen // Journal of Southwest Petroleum University. - 1 February 2017. - V. 39. - Iss. 1. P. 114-123. комплексе Tempest More выполнено моделирование работы элемента с этой скважиной при условии, что по аналогии со скв. 351 приемистость верхнего интервала снизится на 80 \% при проведении ВПП с водоизоляционным составом. По добывающим скважинам в течение года обводненность снижается на $3 . . .15 \%$, суммарный дебит по нефти увеличивается на 0,9 т/сут. На скважине 727 ранее было проведено радиальное бурение и по радиальным каналам наблюдается опережающее обводнение. При моделировании комплексного воздействия (одновременно на добывающей и нагнетательной скважинах), а именно ВПП на скв. 779 и водоизоляционных работ на скв. 727 с применением гелеобразующего состава, по добывающим скважинам в течение 24 месяцев обводненность снижается более чем на $6,9 \%$.

\section{Заключение}

Дана оценка результатов выполненных на нефтяных месторождениях Пермского Прикамья водоизоляционных и потоковыравнивающих работ на скважинах. Отмечена более высокая эффективность применения для карбонатных коллекторов Ножовской группы месторождений осадкогелеобразующего состава на основе технических лигносульфонатов. Выполнено гидродинамическое моделирование эффективного комплексного воздействия для нагнетательной и добывающей скважин на участке турнейской залежи Березовского месторождения. Снижение обводненности по результатам моделирования через 24 месяца составило 6,9\%, дополнительная добыча нефти 880 т.

6. Hou J., Luo M., Zhu D. Foam-EOR method in fractured-vuggy carbonate reservoirs: mechanism analysis and injection parameter study // Journal of Petroleum Science and Engineering. May 2018. - V. 164. - P. 546-558.

7. Поплыгина И.С. Возможности повышения эффективности разработки залежи с высоковязкой нефтью на территории Пермского края // Вестник Пермского национального исследовательского политехнического университета. Геология. Нефтегазовое и горное дело. - 2014. - Т. 13. - № 11. - С. 57-66.

8. Гладких Е.А., Хижняк Г.П. Результаты исследований водоизоляционного состава на керновой модели слоисто-неоднородного пласта // Нефтяное хозяйство. - 2017. - № 11. C. $118-121$

9. Строганов М.А. Технологии выравнивания профиля приемистости нагнетательных скважин с применением кремнийорганических тампонажных материалов группы АКОР // Нефть. Газ. Инновации. - 2016. - № 4. - С. 69-73.

10. Абилхаиров Д.Т., Альмухаметова Э.М., Владимиров И.В. Результаты внедрения технологии выравнивания профиля приемистости с применением Геллана в качестве тампонирующего агента // Нефтегазовое дело. - 2017. - Т. 15. - № 1. - С. 65-69.

11. Хасанов И.М. Результаты применения технологий по выравниванию профилей приемистости (ВПП) нагнетательных скважин на месторождениях А0 «Варьеганнефтегаз» // Нефть. Газ. Инновации. - 2015. - № 7. - С. 28-33.

12. Юшков И.Р., Цветков Г.А. Итенсификация добычи высоковязкой нефти Опалихинского месторождения // Вестник 
Пермского университета. Геология. - 2017. - Т. 16. - № 1. C. $84-90$.

13. Gao C., Shi J., Zhao F. Successful polymer flooding and surfactant-polymer flooding projects at Shengli Oilfield from 1992 to 2012 // Journal of Petroleum Exploration and Production Technology. - V. 4. - Iss. 1. - March 2014. - P. 1-8.

14. Polymer flood application to improve heavy oil recovery at East Bodo / F.R. Wassmuth, W. Arnold, K. Green, N. Cameron // Journal of Canadian Petroleum Technology. - 2009. - V 48 (2). P. $55-61$.

15. Integrating genetic algorithm and support vector machine for polymer flooding production performance prediction / J. Hou, Z.-q. Li, X.-l. Cao, X.-w. Song // Journal of Petroleum Science and Engineering. - V. 68. - Iss. 1-2. - September 2009. P. 29-39.

16. Мордвинов В.А., Поплыгин В.В., Поплыгина И.С. Варианты полимерного заводнения залежи с высоковязкой нефтью // Вестник Пермского национального исследовательского политехнического университета. Геология. Нефтегазовое и горное дело. - 2015. - Т. 14. - № 14. - С. 39-51.

17. Oilfield reservoir souring during waterflooding: a case study with low sulphate concentration in formation and injection waters /
A.N. Cavallaro, M.E.G. Martinez, H. Ostera, H. Panarello, R.R. Cordero // Proc. - SPE International Symposium on Oilfield Chemistry. -2005. - SPE 92959. - P. 131-142.

18. Водоизоляционные работы в условиях конусообразования / А.В. Распопов, А.С. Казанцев, С.А. Кондратьев и др. // Нефтяное хозяйство. - 2015. - № 11. - С. 118-120.

19. Опыт и перспективы применения технологий ограничения водопритока на месторождениях Пермского края / А.В. Распопов, А.С. Казанцев, Д.В. Андреев, И.В. Аверина, Д.Д. Сидоренко, С.Н. Глазырин // Геология, геофизика и разработка нефтяных и газовых месторождений. - 2016. - № 9. C. $41-45$.

20. Антонов Ю.Ф., Мордвинов В.А Исследование алюмосодержащих составов для регулирования профилей приемистости скважин // Геология, геофизика и разработка нефтяных и газовых месторождений. - 2005. - № 9-10. - С. 57-60.

21. Антонов Ю.Ф., Мордвинов В.А. Результаты обработок нагнетательных скважин Усть-Балыкского месторождения осадкообразующим составом // Наука - производству. - 2006. № 1. - C. 37-38.

Поступила 28.02.2019 2.

\section{Информация об авторах}

Поплыгина И.С., аспирант кафедры нефтегазовых технологий Пермского национального исследовательского политехнического университета.

Мордвинов B.A., кандидат технических наук, доцент кафедры нефтегазовых технологий Пермского национального исследовательского политехнического университета. 


\title{
USING A GEL-FORMING COMPOSITION TO REDUCE THE WATER REHABILITATION OF OIL WELLS WITH HIGH-VISION OIL
}

Irina S. Poplygina',

davydova_irina@bk.ru

\author{
Viktor A. Mordvinov', \\ mva44@bk.ru \\ 1 Perm National Research Polytechnic University, \\ 29, Komsomolsky avenue, Perm, 614990, Russia.
}

Relevance. Flooding of producing wells is a natural process in oil field exploration. Well irrigation is primarily affected by reservoir heterogeneity in terms of filtration properties - stratified (along the section) and zonal (along strike), presence of bottom water, oil-water zones, and increased viscosity of reservoir oil. The front movement speed increases in highly permeable layers, which speeds up the premature watering of the wells.

The aim of the research is to evaluate the most effective waterproofing technologies in the Perm region and explore the possibility of using them in an oil field.

Object: carbonate deposits with high-viscosity oil of the Nozhovskoy group of fields in the Perm region. The average viscosity of reservoir oil for 8 development objects in deposits of the turnaiskii stage $(T)$ is $72,1 \mathrm{MPa}{ }^{*}$, with a high value of dissection coefficient $(6,23)$. Average values of water cut and oil recovery ratio reach 1,8. In such conditions, methods of well insulation are widely used.

Methods: analysis of the results of the work performed to reduce well water-cut, hydrodynamic modeling of water insulation works in wells in an oil field.

Results. In the Perm region, higher efficiency while limiting the inflow of water to producing wells by the washed layers for reservoirs with a carbonate reservoir is noted for gelling and sedimentation technologies. In injection wells, work on alignment of injectivity profiles was carried out mainly with the use of cements, resins and polyacrylamide. The high efficiency of use was shown by the technology with sediment- and gelling components based on lignosulfonates. The authors have simulated the operation of the element of the reservoir using sedimentary and gelling agents for the Berezovsky oil field site. It was believed that the pickup of the upper interval will decrease by $82 \%$ during flooding works. For producing wells during the year, the water cut decreases by $3 . .15 \%$, and the total oil flow rate increases by $0,9 t /$ day.

\section{Key words:}

Water cut, waterproofing, sediment-forming technologies, lignosulfonates.

\section{REFERENCES}

1. Liang S., Liu Y., Zhang N., Zeng B. Study on the influence of injection/production type and well pattern and spacing on producing degree of thin and poor layers. Journal of Petroleum Exploration and Production Technology, 1 September 2018, vol. 8, Iss. 3, pp. 861-870.

2. Kudryashova D.A. Use of probabilistic and statistical methods for determination of the sources of water flow in candidate wells for water shut-off works (on example of the Visean reservoir of the Perm region field). Perm Journal of Petroleum and Mining Engineering, 2018, vol. 17, no. 1, pp. 26-36. In Rus.

3. Kochneva 0.E., Limonova K.N. Evaluation water cutting wells and product Yasnopolyanskaya superhorizon Moskudinskogo deposit. Perm Journal of Petroleum and Mining Engineering, 2014, vol. 13, no. 10, pp. 66-72. In Rus.

4. Liu C., Li K., Tian X., Zhao G., Chen Y., Mahlalela B.M. Experimental studies on production performance of oil reservoirs with bottom water. Journal of Petroleum Science and Engineering, January 2019 , vol. 172 , pp. 527-537.

5. Min H., Chen L., Wang L., Zhang L., Chen J. Characteristics and mechanism of water production for fractured vuggy carbonate reservoirs, Halahatang Oilfield. Journal of Southwest Petroleum University, 1 February 2017, vol. 39, Iss. 1, pp. 114-123.

6. Hou J., Luo M., Zhu D. Foam-EOR method in fractured-vuggy carbonate reservoirs: Mechanism analysis and injection parameter study. Journal of Petroleum Science and Engineering, May 2018, vol. 164, pp. 546-558.

7. Poplygina I.S. Opportunities of improved development of highviscosity oil pool in Perm kray. Perm Journal of Petroleum and Mining Engineering, 2014, vol. 13, no. 11, pp. 57-66. In Rus.
8. Gladkikh E.A., Khizhniak G.P. Results of research of waterproofing composition on a core model of a layered heterogeneous. Oil Industry, 2017, no. 11, pp. 118-121. In Rus.

9. Stroganov M.A. Tekhnologii vyravnivaniya profilya priemistosti nagnetatelnyh skvazhin s primeneniem kremniyorganicheskikh tamponazhnykh materialov gruppy AKOR [Technology of leveling injectivity profile of injection wells with the use of silicone tampo-materials of the AKOR]. Neft. Gas. Novatsii, 2016, no. 4, pp. 69-73.

10. Abilkhairov D.T., Almukhametova E.M., Vladimirov I.V. Results of applying new technology injectivity profile alignment of gellan as agent plugging. Oil and gas business, 2017, vol. 15, no. 1, pp. 65-69. In Rus.

11. Khasanov I.M. Rezultaty primeneniya tekhnologiy po vyravnivaniyu profiley priemistosti (VPP) nagnetatelnykh skvazhin na mestorozhdeniyakh A0 «Vareganneftegaz» [Results of applying technologies for leveling injectivity profiles (WFP) of injection wells at the fields of Varioganneftegaz JSC]. Neft. Gas. Novatsii, 2015, no. 7, pp. 28-33.

12. Yushkov I.R., Tsvetkov G.A. Intensification of highly-viscous oil recovery at the Opalikhinskoe field. Bulletin of Perm University. Geology, 2017, vol. 16, no. 1, pp. 84-90. In Rus.

13. Gao C., Shi J., Zhao F. Successful polymer flooding and surfactant-polymer flooding projects at Shengli Oilfield from 1992 to 2012. Journal of Petroleum Exploration and Production Technology, March 2014, vol. 4, Iss. 1, pp. 1-8.

14. Wassmuth F.R., Arnold W., Green K., Cameron N. Polymer flood application to improve heavy oil recovery at East Bodo. Journal of Canadian Petroleum Technology, 2009, vol. 48 (2), pp. 55-61. 
15. Hou J., Li Z.-q., Cao X.-l., Song X.-w. Integrating genetic algorithm and support vector machine for polymer flooding production performance prediction. Journal of Petroleum Science and Engineering, September 2009, vol. 68, Iss. 1-2, pp. 29-39.

16. Mordvinov V.A., Poplygin V.V., Poplygina I.S. Methods of polymer flooding of high-viscosity oil pools. Perm Journal of Petroleum and Mining Engineering, 2015, vol. 14, no. 14, pp. 39-51. In Rus.

17. Cavallaro A.N., Martinez M.E.G., Ostera H., Panarello H., Cordero R.R. Oilfield reservoir souring during waterflooding: A case study with low sulphate concentration in formation and injection waters. Proceedings - SPE International Symposium on Oilfield Chemistry, 2005, no. SPE 92959, pp. 131-142.

18. Raspopov A.V., Kazantsev A.S., Kondratev S.A. Water shutoff treatment under water coning. Oil Industry, 2015, no. 11, pp. 118-120. In Rus.
19. Raspopov A.V., Kazantsev A.S., Andreev D.V., Averina I.V., Sidorenko D.D., Glazyrin S.N. Experience and prospects of application of water inflow limitation in the firlds of Perm region. Geology, geophysics and development of oil and gas fields, 2016, no. 9, pp. 41-45. In Rus.

20. Antonov Yu.F., Mordvinov V.A Research of aluminum-containing compositions for the regulation of wells acceptance profile. Geology, geophysics and development of oil and gas fields, 2005, no. 9-10, pp. 57-60. In Rus.

21. Antonov Yu.F., Mordvinov V.A. Rezultaty obrabotok nagnetatelnykh skvazhin Ust-Balykskogo mestorozhdeniya osadkoobrazuyushchim sostavom [Results of the cutting well handling of the Ust-balyk deposit with a drain formulating composition]. Nau$k a-$ proizvodstvu, 2006, no. 1, pp. 37-38.

Received: 28 February 2019.

\section{Information about the authors}

Irina S. Poplygina, postgraduate student, Perm National Research Polytechnic University.

Viktor A. Mordvinov, Cand. Sc., associate professor, Perm National Research Polytechnic University. 